\title{
Um ator influente com interesse em modelos educativos estrangeiros: José Maria Eugénio de Almeida (1811-1872)
}

\section{(José Maria Eugénio de Almeida (1811-1872): his interest in foreign educational models and influence on education in Portugal)}

\author{
Carlos MANIQUE DA SILVA \\ Instituto de Educação da Universidade de Lisboa \\ Unidade de Investigação \& Desenvolvimento em Educação e Formação
}

\begin{abstract}
RESUMO: O presente artigo contextualiza a ação educativa de um prestigiado membro da elite económica e política portuguesa de meados do século XIX - José Maria Eugénio de Almeida (1811-1872). Enfatizando a circulação internacional do conhecimento, revela-se 0 interesse que os sistemas educativos dos Estados alemães suscitam a Eugénio de Almeida. As viagens pedagógicas que realiza a alguns desses Estados alicerçam o processo de renovação pedagógica que terá lugar na Casa Pia de Lisboa - instituição assistencial que lidera entre 1859 e 1872. No fundo, aquilo que se pretende conhecer é o impacto que esse "contacto" (estrangeiro) tem no sistema existente. Verdadeiramente, o posicionamento concetual é o de perceber como uma realidade (a da Casa Pia de Lisboa) é pensada em função de um referente estrangeiro. Por outras palavras, na linha da investigação de Mary S. Morgan, significa que no contexto de receção há acomodação e adaptação do conhecimento. No entanto, a sua integridade não é posta em causa.
\end{abstract}

PALAVRAS CHAVE: Casa Pia de Lisboa; José Maria Eugénio de Almeida; circulação do conhecimento pedagógico; viagens pedagógicas; escola graduada.

ABSTRACT: The article explores the social and historical background of the educational activities of José Maria Eugénio de Almeida (1811-1872), a prestigious member of the Portuguese economic and political elite of the mid-nineteenth century. The study highlights the context of international exchange of ideas and Eugénio de Almeida's particular interest in the German state education systems of the period. His fact-finding tours to some of these states laid the groundwork for the process of pedagogical renewal undertaken at Casa Pia de Lisboa, the educational institution he led for nearly fifteen years (1859-1872). The aim of the study is to assess the impact of this foreign 'contact' on the Portuguese education system of the time and to examine the construction of an alternative educational reality (that of Casa Pia de Lisboa) based on a foreign model. In line with Mary S. Morgan's research on models as experimentable things, the study reveals the successful transmission of Eugénio de Almeida's foreign innovations with the adaptations and accommodations typical of any context of reception. 
KEYWORDS: Casa Pia de Lisboa; José Maria Eugénio de Almeida; pedagogical exchange of ideas; fact-finding tours; graded education

The true greatness of a people does not consist in borrowing nothing from the others, but in borrowing from all whatever is good, and in perfecting whatever it appropriates. (Victor Cousin, 1836)

\section{Introdução}

Para o conhecimento da vida e do percurso profissional de José Maria Eugénio de Almeida (Lisboa, 1811-1872) muito contribuíram os estudos de Hélder Fonseca e Jaime Reis ${ }^{1}$, de Fátima Marvão ${ }^{2}$ e de José Miguel Sardica. ${ }^{3}$ Na verdade, graças a esse labor, conhecemos hoje razoavelmente bem a ação pública e privada de um destacado membro da elite económica e política nacional. Burguês na origem, Eugénio de Almeida soube acumular, no período compreendido entre o cabralismo e as duas primeiras décadas da Regeneração, avultada fortuna. A par da carreira de empresário - iniciada depois de concluída a formatura em leis, na Universidade de Coimbra, corria o ano de 1839 - teve uma vida pública ativa. Com efeito, foi redator do periódico Português Constitucional, parlamentar, provedor da Casa Pia de Lisboa, filantropo, membro de várias comissões, confrade (de irmandades religiosas e misericórdias), par do Reino..., granjeando condecorações e distinções honoríficas. Como bem refere José Miguel Sardica, "o dinheiro e padrão de vida aristocrático de que inegavelmente usufruiu jamais fizeram dele um novo-rico, insensível aos assuntos da cultura, do espírito ou da caridade". ${ }^{4}$

As palavras que acabei de citar motivam o presente artigo. Na verdade, o meu propósito não é abordar a faceta económica e empresarial de José Maria Eugénio de Almeida (certamente, a mais estudada e divulgada). Interessa-me, sim, olhar para a sua intervenção pública através de outro ângulo. Refiro-me ao homem envolvido na administração de uma instituição eminentemente caritativa e assistencial - a Casa Pia de Lisboa -, da qual foi provedor no período compreendido entre 1859 e 1872, promovendo, de resto, uma importante reforma dos estudos. Ora, não é possível falar dessa reforma - que introduz, aliás, o modelo de escola graduada em Portugal - sem perceber o "espírito" do seu mentor (e as influências que recebeu), razão pela qual, numa primeira parte deste texto, analisarei os seguintes aspetos: i) formação académica de Eugénio de Almeida; ii) a forma como se instruía e atualizava no sentido de desempenhar os cargos para os quais era investi-

\footnotetext{
${ }^{1}$ Hélder Fonseca and Jaime Reis, "José Maria Eugénio de Almeida, um capitalista da Regeneração", Análise Social, (XXIII) 99 (1987): 865-904.

2 Fátima Marvão, "Moralização, Trabalho e Educação. O Projecto Educativo da Casa Pia de Lisboa (1852-1922)". (Dissertação de mestrado, Universidade de Lisboa/ Faculdade de Psicologia e de Ciências da Educação, 2004). ${ }^{3}$ José Miguel Sardica, José Maria Eugénio de Almeida: Negócios, Política e Sociedade no Século XIX. (S.I.: Fundação Eugénio de Almeida, 2016).

${ }^{4}$ Ibidem, 199.
} 
do, sabendo-se, à partida, que o referente estrangeiro tinha para ele especial significado. Neste último aspeto, o que está em questão, por exemplo, é saber que circunstâncias no contexto de origem (Casa Pia de Lisboa) criaram a necessidade de olhar experiências educativas estrangeiras. ${ }^{5}$ Por outro lado, interessa identificar que país ou países exerceram especial atração e, mesmo, que modelos educativos foram privilegiados. Importa, por fim, perceber qual o impacto desse "contacto" no sistema existente. E aqui a minha posição é muito próxima da que é defendida por Mary S. Morgan: "As knowledge travels from one community to another, it has to be translated and in the process changes to some degree its meaning and thus, necessarily loses some of its integrity in travelling". ${ }^{6}$

\section{Eugénio de Almeida: formação académica, cultura e atualização de conhecimentos}

Há uma frase de D. António da Costa - o primeiro ministro da Instrução Pública de Portugal - que define José Maria Eugénio de Almeida nos seguintes termos: "pensava, lia e visitava com utilidade os estabelecimentos estrangeiros". " Na minha opinião, são palavras que encaixam perfeitamente no perfil de Eugénio de Almeida. $O$ facto de ser uma pessoa que procurava informar-se, estudando a fundo os assuntos, não é certamente alheio à sólida formação académica que recebeu. Com efeito, foi a longa educação em S. Vicente de Fora, um prestigiado colégio oratoriano de Lisboa, que Ihe "moldou os traços para toda a vida", para seguir à letra Hélder Fonseca e Jaime Reis. ${ }^{8}$ E a verdade é que nunca deixou de se atualizar ao longo da vida.

José Maria Eugénio de Almeida foi, seguramente, um homem com preocupações culturais, mesmo considerando que a média de gastos anuais com essa "rubrica" nunca chegou a atingir os $8 \%$ dos gastos totais de toda a sua casa. ${ }^{9}$ Atesta-0, claramente, a biblioteca privada que reuniu entre a década de 1840 e o final da vida (uma das mais vastas de entre os seus contemporâneos). Do catálogo da referida biblioteca constam 2031 espécies, classificadas (pelo próprio Eugénio de Almeida) de acordo com as seguintes categorias: i) Ciências Eclesiásticas; ii) Ciências Morais e Políticas; iii) Ciências Naturais e Exatas; iv) Belas-Artes e Ofícios; v) Literatura; vi) História. ${ }^{10}$

Aquilo que pretendo sublinhar, na linha, aliás, de outros investigadores, é que o acervo em causa não se destinava apenas a recreação do espírito. ${ }^{11} \mathrm{Na}$ verdade, grande parte dos livros, jornais, revistas e brochuras que compunham a biblioteca estavam diretamente relacionados às áreas profissionais do seu detentor - que prezava, em muito, a informação

\footnotetext{
${ }^{5}$ David Phillips, "Toward a Theory of Policy Attraction in Education", en The Global Politics of Educational Borrowing and Lending, ed. Gita Steiner-Khamsi (New York: Teachers College, Columbia University, 2004), 54-67. ${ }^{6}$ Mary S. Morgan, "Travelling Facts", en How Well do Facts Travel?, ed. Mary S. Morgan y Peter Howlett (New York: Cambridge University Press, 2011), 13.

${ }^{7}$ D. António da Costa, Auroras da Instrucção pela Iniciativa Particular (Coimbra: Imprensa da Universidade, 1885), 118.

${ }^{8}$ Fonseca and Reis, "José Maria Eugénio de Almeida", 870.

${ }^{9}$ Sardica, José Maria Eugénio de Almeida.

${ }^{10} \mathrm{Cf}$. Arquivo da Fundação Eugénio de Almeida, Catalogo Methodico da Livraria do llustríssimo e Excelentíssimo Senhor José Maria Eugenio de Almeida Organizado no anno de 1867 e Ampliado em 1873.

${ }^{11}$ Fonseca and Reis, "José Maria Eugénio de Almeida"; Sardica, José Maria Eugénio de Almeida.
} 
prática. Não surpreende, por conseguinte, a existência de livros sobre jurisprudência, administração, instrução pública, finanças, comércio, indústria, agricultura e economia rural.

No presente artigo, julgo útil ensaiar uma classificação (com o que isso tem de artificial) das obras sobre educação e instrução pública que integram a biblioteca de Eugénio de Almeida. Por razões metodológicas vou apenas considerar o catálogo elaborado em 1867, uma vez que é o único que reúne praticamente a totalidade dos livros que foram adquiridos por Eugénio de Almeida. Falo, no citado campo, de cerca de 20 títulos, totalizando pouco mais de 40 volumes. Com efeito, o catálogo organizado em 1873 (portanto, já depois do falecimento de Eugénio de Almeida), não nos dá essa garantia. $E$ há outra questão para a qual se impõe chamar a atenção. Como se viu, a classificação adotada por Eugénio de Almeida não considera a categoria "educação e instrução pública", quando, na verdade, há títulos que, certamente, nela poderiam ser integrados. Considere-se, entre outros exemplos, a obra de Charles Jourdain, Le Budget de l'Instruction Publique et des Établissements Scientifiques et Littéraires... (Paris, 1857), classificada na subcategoria "Finanças".

Posto isto, devo referir que estabeleci as seguintes quatro categorias: i) Relatórios/ Estudos sobre os sistemas educativos de países da Europa; ii) Obras/ Tratados sobre educação de autores estrangeiros e nacionais de referência; iii) Publicações sobre processologia-didática; iv) Relatórios/ Estudos versando o sistema educativo português.

No universo considerado, e sem pretender quantificar, é sobretudo expressivo o número de Obras/ Tratados sobre educação de autores estrangeiros e nacionais de referência (reporto-me, particularmente, às dimensões teóricas da educação). Nesta categoria podemos incluir estudos dedicados à moral e à educação, como sejam, a título de exemplo: as Lettres de Famille sur l'Éducation (Paris, 1854), da autoria de Madame Guizot; os Entretiens sur l'Éducation des Filles (Paris, 1854), de Madame de Maintenon; as Nouvelles Genevoises (Paris, 1842), de Rodolphe Töpffler; ou, mesmo, os Conseils aux familles sur la manière d'élever les enfants, suivis d'un précis d'Hygiène (Paris, 1864), de Alfred Donné. Há, por outro lado, obras cujo foco é a relação entre educação e ordem social, caso paradigmático do Essai sur l'émulation dans l'ordre social et son application à l'éducation (Genève, 1802), de George-Marie Raymond. Indicaria, ainda, em lugar à parte, por se tratar de um verdadeiro tratado de pedagogia, De l'Éducation (Orléans, 1850-57?), de Dupanloup, bispo de Orléans. No mesmo sentido, cabe referir o seminal trabalho de Luís António Verney, Verdadeiro Método de Estudar ([Nápoles], 1747). Todas as obras mencionadas são de autores consagrados (e em voga no tempo em que publicaram); a esmagadora maioria foram dadas à estampa no século XIX, em Paris, e escritas em língua francesa; a exceção, praticamente, é a obra de Verney.

Por outro lado, é evidente o equilíbrio de títulos dizendo respeito às seguintes categorias: Relatórios/ Estudos sobre países estrangeiros; Relatórios/ Estudos versando o sistema educativo português. Citaria, no primeiro caso, alguns relatórios sobre a situação da instrução primária, secundária e superior na Bélgica, nos finais da década de 1850 e inícios da década seguinte; no segundo caso, apontaria o Relatório sobre a visita de 
inspeção extraordinária às escolas do distrito de Lisboa (Lisboa, 1865), de Mariano Ghira, bem como a História da instrução popular em Portugal (Lisboa, 1871), de D. António da Costa.

Refira-se, por fim, que é diminuta a existência de títulos sobre processologia-didática; em bom rigor, apenas um pode ser incluído nessa categoria: o Nouveau Manuel des écoles primaires, moyennes et normales (Paris, 1834).

Face ao exposto (e, também, ao que não se afigura explícito), que conclusões se podem retirar quanto à orientação das leituras? Dir-se-ia, em primeiro lugar, que no acervo há um peso muito significativo de obras ligadas às questões da moral e da educação; se quisermos, à ideia de regeneração e moralização da sociedade através da escola, sem deixar de parte, é bom frisar, a educação feminina. Por outro lado, é patente que há um interesse por temas mais "técnicos", ou seja, que se prendem com o conhecimento específico da organização dos sistemas educativos (sobretudo estrangeiros). Estas primeiras notas não se afiguram surpreendentes, se pensarmos que a biblioteca foi essencialmente constituída em função dos interesses profissionais do seu detentor; presidiu, pois, à sua composição uma perspetiva utilitarista (e funcionalista).Também não se estranha a ausência de obras escritas pelos grandes pedagogos de finais do século XVIII/ primeiras décadas da centúria seguinte, a exemplo de Pestalozzi, Froebel e Herbart, às quais Eugénio de Almeida poderia ter facilmente acedido nos livreiros das capitais da Europa por onde passou.

No catálogo de 1867 (que segui, lembro) não encontramos, por exemplo, monografias sobre instituições de ensino ou, mesmo, estatutos de instituições de ensino e de assistência nacionais e estrangeiros. Mas, atendendo à fonte, a análise que fiz foi muito restritiva. Suspeito que há títulos, não integrados nos catálogos de 1867 e de 1873, mas que se encontram hoje na biblioteca da Fundação, que poderão ter sido adquiridos por José Maria Eugénio de Almeida. $O$ exemplo paradigmático é o da obra Notice sur l'école préparatoire annexée a la colonie de Mettray (Paris, 1860), colónia destinada a regenerar os jovens mais problemáticos e que Eugénio de Almeida visitou em finais da década de 1850; Mettray (muito em voga em meados de Oitocentos) influenciou, aliás, conforme veremos, a conceção de assistência pública de Eugénio de Almeida.

\section{A importância das viagens extrafronteiras: conhecer para agir}

Entre 1845 e 1867, José Maria Eugénio de Almeida realizou um conjunto de viagens ao estrangeiro. Recenseei nove estadas fora do país, embora seja provável que esse número peque por defeito. Enunciemo-las:

1845 - Londres, Paris, Bruxelas, Bruges, Anvers, Southampton, Londres.

1849 - Londres e Paris.

1851 - Londres (Grande Exposição Internacional).

1857 - Madrid, Paris, Londres. 
1858 (3 de julho a 24 de novembro) - Madrid, Sant Étienne, Bayonne, Bordéus, Poitiers, Paris, Calais, Londres, Dover.

1861 (15 de junho a 28 de outubro) - Bordéus, Paris, Tours, Versailles, Fontainebleau, Dijon, Lyon, Berna, Genebra, Lausanne, Frankfurt, Munique, Estugarda, Nuremberga, Colónia, Bruxelas, Paris.

1862 - Londres (Exposição Internacional).

1863 - Dresden, Gotha?

1867 (27 de julho a 17 de novembro) - Badajoz, Ciudad Real, Madrid, Biarritz, Paris, Bordéus, Estrasburgo, Baden-Baden, Nancy, Chalons, Valadolid, Escorial, Badajoz. ${ }^{12}$

De algumas dessas viagens temos registo pormenorizado das despesas. ${ }^{13}$ Para Eugénio de Almeida - e esse é o ponto que me interessa sublinhar - as referidas viagens tiveram importância a vários títulos. Quero com isto dizer que serviram simultaneamente diversos fins. Foram, é certo, viagens de negócios. Em julho de 1845, por exemplo, encontrando-se em Paris com o objetivo de comprar maquinaria e de entabular contactos no mundo industrial, cruzou-se na Ópera Cómica com Júlio Máximo de Oliveira Pimentel, lente da cadeira de Química na Escola Politécnica de Lisboa. ${ }^{14}$ Eugénio de Almeida formulou-Ihe então um convite: 0 de dirigir a fábrica de Saboaria do Poço do Bispo, o qual foi aceite. Espírito rápido e empreendedor, Eugénio de Almeida incumbiu imediatamente Pimentel de ir a Marselha com o intuito de estudar os métodos de fabrico utilizados nas indústrias do sabão, pagando as respetivas despesas (as quais ficaram lavradas no caderno de despesas da viagem).

Por outro lado, foram também viagens de prazer, se preferirmos, de fruição cultural. Em 1845, por exemplo, encontrando-se em Anvers, aproveita para conhecer o jardim zoológico local. Nessa mesma viagem, já em Londres, visita o telégrafo elétrico. E não faltam as visitas a monumentos (Versalhes e Escorial, em 1867), só para mencionar dois exemplos.

Ao mesmo tempo foram viagens que visaram, em particular, conhecer projetos de intervenção e instituições ligadas à regeneração de jovens (orfanatos, colónias...). Preocupação, aliás, muito presente em Eugénio de Almeida desde os anos de 1840. A esse facto também não terá sido estranha a sua formação religiosa e humanista. Há, ainda, a considerar o interesse por outro tipo de instituições de ensino (universidades, politécnicos, conservatórios, escolas de formação de professores...) e, mesmo, pelo sistema penitenciário em geral. Vejamos alguns exemplos. Em 1845 visitou, em Londres, a Escola Politécnica; em Paris, o Conservatório das Artes e Ofícios; em Bruges,

\footnotetext{
${ }^{12}$ São as seguintes as fontes que permitiram o recenseamento das referidas viagens: Fundação Eugénio da Almeida, "Fundo para as despesas das minhas viagens a países estrangeiros, em 1845"; Idem, "Contas das despesas pessoais, viagens a países estrangeiros..."; Fonseca and Reis, "José Maria Eugénio de Almeida"; Sardica, José Maria Eugénio de Almeida; Marvão, Moralização, Trabalho e Educação.

${ }^{13} \mathrm{Cf}$. Arquivo da Fundação Eugénio de Almeida.

${ }^{14}$ Guilhermina Mota, "O Visconde de Vila Maior: alguns apontamentos sobre a sua vida e ação", Biblos X (2012): 246-292.
} 
a Universidade e a Penitenciária. Em 1858, passou por Mettray, visitando a famosa colónia penitenciária destinada a regenerar jovens delinquentes. Já em 1861, e lembro que desde 1859 era provedor da Casa Pia de Lisboa, em Genebra e em Berna, visitou orfanatos. Dois anos mais tarde, na Alemanha, num périplo muito orientado para 0 conhecimento do ensino da ginástica, visita a Escola Normal de Dresden, na Saxónia, com a qual fica impressionado. É também provável que, nessa visita à Alemanha, tenha conhecido a célebre escola de Schnepfenthal, fundada no final do século XVIII e modelo em educação física. ${ }^{15}$

É, pois, o homem que procurei retratar - de cultura, profundo conhecedor de várias áreas e dando importância ao referente estrangeiro - que liderará, a partir de 1859 e até ao final da vida, uma instituição de ensino muito singular - a Casa Pia de Lisboa - implementando um projeto educativo inovador.

\section{A Reforma dos Estudos na Casa Pia de Lisboa}

Em 1859, José Maria Eugénio de Almeida assume o cargo de provedor da Casa Pia de Lisboa. ${ }^{16}$ Uma missão que aceitou desempenhar por serviço à causa pública. Tratouse, na verdade, de um ato benemerente e de grande desprendimento, uma vez que prescindiu do vencimento a que tinha direito, doando-o, todos os meses, à instituição que ia liderar.

É certo que Eugénio de Almeida conhecia as dificuldades por que passava a Casa Pia de Lisboa. Abraçava, assim, uma tarefa árdua. Por exemplo, o número de órfãos era excessivo (quase a rondar os 1000), o espaço físico era exíguo e sem condições de salubridade, propiciando o desenvolvimento de várias doenças contagiosas.

Não surpreende, dessa forma, que as primeiras medidas de Eugénio de Almeida tenham exatamente que ver com a tentativa de resolver os problemas enunciados. Impunhase, pois, uma reforma radical, antes mesmo de olhar a questões (dir-se-ia) puramente pedagógicas; reforma que passava, obrigatoriamente, pela redução do número de órfãos e pela reconstrução do edifício.

A reforma que vai então empreender evidencia um homem a par dos ideais filantrópicos e dos princípios higienistas em voga na Europa, algo que não se afigura surpreendente se nos lembrarmos do perfil que tracei de Eugénio de Almeida.

Achou prudente, porém, não revogar o decreto de 9 de maio de 1835, o qual, à data, enquadrava toda a administração da instituição e fixava, por exemplo, em 1000 o número de órfãos. No relatório da administração da Casa Pia que publicou em 1861 afirma perentoriamente: "acima do decreto de 9 de maio de 1835 há as leis da verdade e da humani-

\footnotetext{
${ }^{15}$ Carlos Manique da Silva, "Do modo de aprender e de ensinar: renovação pedagógica e cenários de experimentação da escola graduada (1834-1892)" (Tese de doutoramento, Universidade de Lisboa/ Faculdade de Psicologia e de Ciências da Educação, 2008).

${ }^{16}$ A Casa Pia de Lisboa, instituição destinada a acolher e integrar socialmente órfãos do sexo masculino, foi fundada em 1780, a instâncias de Diogo Inácio de Pina Manique.
} 
dade, que, como leis que são da Providência, têm uma autoridade sublime e uma força irresistível que dominam e fazem emudecer a dos decretos humanos". ${ }^{17}$

Assim, sem ofender o referido decreto adota as seguintes medidas: suspender as admissões; promover a saída voluntária de órfãos, apoiando as famílias que o pretendessem fazer. Mais, e respeitando a letra do decreto de 9 de maio de 1835, Eugénio de Almeida ordenou que todos os órfãos do sexo masculino que excedessem a idade definida no referido diploma abandonassem a instituição. Tratava-se, no fundo, de desacumular o internato para um número de alunos que seria financeiramente suportável (eram crónicos os deficits da Casa Pia), visando, ao mesmo tempo, melhorar as condições higiénicas.

Se atentarmos nas portarias da Casa Pia de Lisboa que são publicadas ao longo do ano de $1860^{18}$, ficamos, claramente, com a ideia de que Eugénio de Almeida, num momento inicial, se preocupou com questões relativas à higiene e ao desenvolvimento físico dos alunos. Aliás, a educação física constituirá uma das linhas de força do seu projeto pedagógico. Por exemplo, a portaria n. ${ }^{\circ} 30$, de 20 de março de 1860, ordena que os órfãos tenham horas para recreios, restabelecendo ao mesmo tempo a escola de ginástica; por seu turno, a portaria $n .-56$, de 8 de agosto do referido ano, estabelece uma casa de banhos.

Não menos relevante é a portaria n. ${ }^{\circ} 33$, de 29 de março de 1860, que organiza um colégio com a denominação "Colégio dos Inválidos", cujo objetivo era o de apartar os órfãos que, pelo seu estado físico, não podiam estar sujeitos ao internato comum.

Mas também é verdade, como bem elucida Fátima Marvão, que a preocupação com a preguiça e o ócio, bem como com o ódio ao trabalho são uma constante no discurso pedagógico de Eugénio de Almeida. ${ }^{19}$ Se recuperarmos a primeira página da Notice sur le école preparatoire annexé à Mettray, percebemos que o que estava em causa era a regeneração de jovens (delinquentes, em muitos casos) através do trabalho e da religião - era, pois, possível recuperá-los para a sociedade (algo que se afigurava bem diferente de encarcerá-los apenas, considerando-os ineducáveis). Assim, para além da educação intelectual e moral/ religiosa, era indispensável o aprendizado de um ofício. Também neste último domínio Eugénio de Almeida tomou importantes medidas em 1860. Na verdade, substituiu as oficinas que existiam na Casa Pia (de carpinteiro e de ferreiro), cujos resultados eram pouco consequentes, por um colégio de aprendizado dos mesmos ofícios no Instituto Industrial de Lisboa. ${ }^{20}$

Ora, todo esse esforço produziu os melhores resultados. Em 1866, por exemplo, a fazer fé no testemunho do provisor dos estudos, José António Simões Raposo ${ }^{21}$, a ginástica achava-se cientificamente organizada, assim como estavam perfeitamente definidas as

${ }_{17}$ José Maria Eugénio de Almeida, Relatorio da Administração da Real Casa Pia de Lisboa [de 20 de Out. de 1859 a 31 de Out. de 1860] (Lisboa: Imprensa Nacional, 1861), 7.

${ }^{18}$ Portarias da Administração da Real Casa Pia de Lisboa Publicadas pelo Provedor José Maria Eugénio de Almeida (Lisboa: Imprensa Nacional, 1862). Doravante, todas as portarias citadas são extraídas desta publicação.

${ }^{19}$ Marvão, "Moralização, Trabalho e Educação".

${ }^{20}$ Silva, "Do modo de aprender e de ensinar".

${ }^{21}$ Sobre esta personalidade, ver António Nóvoa (dir.), Dicionário de Educadores Portugueses (Porto: ASA, 2003). 
regras de higiene a observar e, mesmo, tudo o que dizia respeito ao regímen alimentar dos órfãos. ${ }^{22}$

Faltava, sobretudo, a reforma da "educação intelectual", da qual me ocuparei agora. Vejamos então qual foi o caminho prosseguido, sendo certo que só em 1866 se encontrou uma definição clara.

Comecemos por perceber o essencial da conceção pedagógica de Eugénio de Almeida e a via que pretendia seguir para reformar a "educação intelectual". Afirmava o provedor no Relatório publicado em 1861:

O que me parece destacar-se, como verdade apurada, do meio de todos os exames e dúvidas, é que a educação literária de que convém tratar na Casa Pia é a primária; e que esta deve ser tão extensa e perfeita quanto for possível. É esse o melhor meio de educar aqui mancebos que tenham aptidão e préstimo para todas as carreiras laboriosas e modestas [...] Se um ou outro tiver de subir a uma instrução mais alta, a instrução primária desenvolvida e aperfeiçoada, que tiver recebido aqui, fará que a outra lhe aproveite melhor. ${ }^{23}$

Ora, sabemos que em 1859 o governo manifesta a intenção de a administração da Casa Pia estabelecer várias escolas de ensino primário divididas em graus, se quisermos, em classes progressivas, algo que era original em Portugal. ${ }^{24} \mathrm{Na}$ verdade, é aqui que começa a desenhar-se a primeira imagem da escola primária moderna - a chamada escola graduada. Explico o conceito: trata-se de uma modalidade que só se produz quando a graduação dos estudos implica a existência de várias aulas de classe ou graus com vários professores, um diretor, classes o mais homogéneas possível e um currículo graduado. ${ }^{25}$

Devo afirmar que o "plano de ensino" elaborado pela instituição, consagrado em Portaria de 10/1/1860, apesar de ser provisório, não divergiu das orientações superiormente emanadas. $\mathrm{O}$ traço estruturante era de facto a divisão do ensino primário (elementar e superior) em graus, não menos de três, nem mais de seis, impondo-se ainda assinalar uma outra medida plena de significado. Esta: ser condição necessária para 0 acesso ao magistério possuir as habilitações exigidas no ensino oficial.

E se à entrada da década de 1860 parecem estar definidas as grandes linhas ordenadoras do projeto educativo casapiano, certo é que até setembro de 1866, momento em que Simões Raposo assume o lugar de provisor dos estudos, não se registam progressos significativos.

Julgo, no entanto, útil descrever os principais passos dessa evolução. De acordo com o Relatório de Eugénio de Almeida, durante o primeiro ano do seu mandato foram cria-

\footnotetext{
${ }^{22}$ Cf. O Ex-Director da Casa Pia de Lisboa Francisco Antonio da Silva Neves e o Actual Director (Lisboa: Typographia da Bibliotheca Nacional, 1881).

${ }^{23}$ Almeida, Relatorio da Administração da Real Casa Pia de Lisboa, 75.

${ }^{24}$ Silva, "Do modo de aprender e de ensinar".

${ }^{25}$ Antonio Viñao, "La Renovación de la Organización Escolar: la escuela graduada", en Psicología y pedagogía en la primera mitad del siglo XX, coord. Gabriela Ossenbach Sauter (Madrid: UNED, 2003), 73-104.
} 
das três "aulas" (leia-se graus) de ensino primário, não obstante apenas duas terem sido providas. À data, lê-se nesse mesmo documento, a questão essencial para o provedor era elevar o número de "aulas" a cinco ou seis, e facultar assim aos alunos a instrução primária superior.

Se nos ativermos ao circunstanciado e insuspeito testemunho do inspetor Mariano Ghira, a situação era em tudo semelhante no ano letivo de $1863-1864 .{ }^{26}$ Porém, é precisamente a partir de 1863 que se intensificam as tentativas para alterar esse estado de coisas. Um acontecimento da maior relevância pedagógica foi por certo a viagem de estudo que Eugénio de Almeida efetuou à Saxónia (segundo creio, nos primeiros meses de 1863). ${ }^{27}$ Num périplo muito orientado para o conhecimento do ensino da ginástica, mostrar-se-ia então de sobremaneira impressionado com a Escola Normal de Dresden. ${ }^{28}$

O vínculo com os Estados alemães manter-se-á nos anos seguintes, conforme prova uma interessante carta dirigida por Eugénio de Almeida ao diretor da Escola de Schnepfenthal, em 14 de março de 1866:

Je désire prêter à mon pays un service que je crois de la plus haute importance, en cherchant à établir et faire connaître pratiquement les bonnes méthodes d'enseignement suivies depuis longtemps en Allemagne et ignorées encore au Portugal.

Je viens donc Monsieur vous demander la grâce de faire inscrire dans la liste de ceux qui attendent une place dans votre école, six (6) élèves de Real Casa Pia de Lisboa, pour y recevoir une éducation élémentaire complète, et suivre en suite le cours d'une des plus célèbres écoles normales allemandes, afin qu'ils puissent plus tard retourner au Portugal et professer ici en suivant les méthodes qu'ils auront appris en Allemagne. ${ }^{29}$

Em si, a missiva espelha a preocupação de Eugénio de Almeida com a preparação pedagógica do professorado, linha de pensamento insistentemente perseguida desde o início do seu mandato (recorde-se a Portaria de 10/1/1860). Sublinho que essa ideia encontra filiação no pensamento do filósofo, historiador, político e reformador francês Victor Cousin (1792-1867). ${ }^{30}$ De resto, na biblioteca de Eugénio de Almeida encontramos o seguinte título da autoria de Cousin: Du vrai, du beau et du bien (Paris, 1853). Mas é muito provável que o provedor da Casa Pia de Lisboa tivesse tido contacto com outras obras do mencionado filósofo. Penso, designadamente, dado 0 seu interesse pela temática da instrução pública, no Rapport sur l'État de l'Instruction Publique dans Quelques Pays de l'Allemagne, et Particulièrement en Prusse (Paris,

\footnotetext{
${ }^{26}$ Mariano Ghira, Relatorio sobre a visita de inspecção ás escolas do districto de Lisboa feita no anno lectivo de 1863-1864 (Lisboa: Typographia Portugueza, 1865).

${ }^{27}$ Em 1861, lembre-se, Eugénio de Almeida visitara já alguns Estados alemães, nomeadamente, a Prússia e a Baviera, assim como o Reino de Wurttemberg.

${ }^{28}$ Silva. "Do modo de aprender e de ensinar".

${ }^{29}$ Arquivo Histórico da Casa Pia de Lisboa, Real Casa Pia de Lisboa, Livro de Registo dos Ofícios para Particulares, n.․1, 1859-1891, 20.

${ }^{30}$ Não estranhamente, na biblioteca de Eugénio de Almeida contam-se também títulos de J. Bentham, Jules Simon, Rousseau, Guizot e Proudhon, entre outros.
} 
1832). ${ }^{31}$ Para a minha agenda de investigação, importa dizer que Cousin enfatiza 0 facto de a Prússia apostar na valorização e na formação dos docentes. Uma ideia bem expressa por Sarah Austin, no prefácio (enquanto tradutora) à versão inglesa da obra: "One of the most important [points] is the absolute necessity of securing a constant supply of well-trained schoolmasters"32; e acrescenta: "Observation long ago convinced me of the entire truth of the maxim laid down by the Prussian government, and approved by M. Cousin, that 'As is the master, so is the school'" ${ }^{33} \mathrm{E}$ é aqui que começa a vislumbrar-se o vínculo que Eugénio de Almeida estabelece com alguns Estados alemães. De facto, o seu intuito é o de assegurar na Casa Pia de Lisboa um corpo docente altamente qualificado; daí, como vimos, a interlocução privilegiada com a Escola de Schnepfenthal. Mas, o foco na mencionada experiência estrangeira tem um fundamento mais profundo. Efetivamente, o que está em causa é o próprio conceito de ensinar, percebido, no contexto dos Estados alemães, como algo mental e reflexivo e não mecânico. ${ }^{34}$ Mais explicitamente, esta questão tem que ver com o processo de receção do ensino mútuo no curso da sua difusão mundial. Sarah Austin - que, como se disse, traduziu e prefaciou a versão inglesa do Relatório de Cousin - elucida-nos a este respeito, criticando, para o efeito, a mecanização imposta por esse modelo (em França e em Inglaterra). Aquilo que pretende fazer sobressair é singularmente expresso na seguinte passagem: "The village schoolmasters of Germany do much more to form the minds of their pupils than Lancaster and Bell can do". ${ }^{35}$ Ora, é importante perceber que o projeto reformador de Eugénio de Almeida vai, justamente, interromper a experiência do ensino mútuo que teve lugar na casa Pia de Lisboa por mais de duas décadas, ou seja, entre 1834 e 1859 (mas com antecedentes). ${ }^{36}$

É a luz de tudo o que foi sendo dito que, em agosto de 1866, num gesto de grande visão pedagógica, o provedor da Casa Pia de Lisboa tome a iniciativa que maior influência terá na organização dos estudos nos anos subsequentes; ou seja, o recrutamento em exclusivo de professores habilitados com o curso normal, incidindo a seleção no universo de antigos alunos pensionistas da Escola Normal de Marvila (Lisboa). ${ }^{37}$ Essa

\footnotetext{
${ }^{31}$ Relatório que teve extrema importância e ampla divulgação. Veja-se, por exemplo, que foi citado por Alexandre Herculano, em 1835, na sua abordagem às escolas da Prússia. Cf. David Justino, Fontismo. Liberalismo numa sociedade iliberal (Lisboa: D. Quixote, 2016).

${ }^{32}$ Victor Cousin, Report on the State of Public Instruction in Prussia (London: Effingham Wilson, Royal Exchange, 1836), xviii.

${ }^{33} \mathrm{lbidem}$

${ }^{34}$ Marcelo Caruso, "Locating educational authority, teaching monitors, educational meanings and the importing of pedagogical models. Spain and German States in the Nineteenth Century", en Educational Policy Borrowing: historical perspectives, ed. David Phillips \& Kimberly Ochs (Oxford: Symposium Books, 2004), 59-87. A este respeito, ver também Henry Barnard, German schools and pedagogy. Organization and instruction of common schools in Germany (New York: F. C. Brownell, 1861).

${ }^{35}$ Victor Cousin, Report on the State of Public Instruction in Prussia, XIX.

${ }^{36}$ Carlos Manique da Silva, "A experiência do ensino mútuo na Casa Pia de Lisboa (1820-1859)", Cadernos de História da Educação 8(1) (2009): 85-101.

${ }^{37}$ É útil referir que, em Portugal, a obrigatoriedade de frequentar 0 ensino normal para aceder ao magistério primário foi decretada em 1901.
} 
opção - que garantia a difusão dos saberes pedagógicos - significou 0 abandono da solução anteriormente considerada por Eugénio de Almeida, isto é, a de enviar alunos para a Escola de Schnepfenthal (hipótese que, a ser seguida, não teria tido retorno imediato). Seja como for, aquilo que me parece importante perceber é o impacto, no contexto de origem, do conhecimento que Eugénio de Almeida granjeou das suas viagens aos Estados alemães.

Uma ideia que é absolutamente central no pensamento de Eugénio de Almeida, pelo menos, desde o início da década de 1860, é a de que só o modelo de escola graduada poderia dar resposta cabal ao projeto de integração social que havia concebido. Não estranha a posição do provedor da Casa Pia de Lisboa, se pensarmos no conhecimento que possuía da realidade educativa dos Estados alemães. Na verdade, nesse contexto, à entrada da década de 1860, "different classes [were] never instructed in the same room", excecionando 0 caso das escolas de aldeias muito pobres..$^{38} \mathrm{O}$ pressuposto de racionalidade que o modelo de escola graduada encerra é bem elucidado por Henry Barnard, na referência à experiência alemã:

This plan of teaching the different classes in different rooms, adds incalculably to the efficiency of the education given. In each room, only one voice is heard at a time - the voice of the teacher or one of the children. The attention of the children is not disturbed or diverted from the teacher by what is going on in another class. Each room is perfectly quiet. ${ }^{39}$

Ora, conforme referi, o plano definido na Portaria de 10/01/1860 previa a divisão do ensino primário em graus (de três a seis) - seguia, de resto, as indicações que 0 governo havia dado à Casa Pia de Lisboa. Para Eugénio de Almeida, o essencial era facultar aos alunos o ensino primário elementar e complementar. No final de outubro do referido ano, a ter em conta o já citado Relatório do provedor da Casa Pia, o ensino primário encontrava-se dividido em três graus. Porém, a partir do ano letivo de 1866/1867, é adotado como norma um modelo de organização pedagógica com seis graus ou cadeiras (o termo mais usado), correspondendo o último grau ao ensino primário complementar. ${ }^{40} \mathrm{~A}$ menor ou maior divisão em graus tem que ver com a necessidade de diferenciação e consecução do currículo. Mas, não podemos esquecer que tal processo combina racionalidades pedagógicas e administrativas que se prendem, por exemplo, com a divisão do trabalho dos docentes. ${ }^{41}$ No caso dos Estados alemães, ao longo da segunda metade do século XIX e até ao início da centúria seguinte, existe alguma variação no que respeita ao número de graus em que a escola primária se encontrava

\footnotetext{
${ }^{38}$ Barnard, German schools and pedagogy, 91.

${ }^{39}$ Ibidem.

${ }^{40}$ Silva, "Do modo de aprender e de ensinar".

${ }^{41}$ Não consegui perceber se, na Casa Pia de Lisboa, a opção de especializar os professores por graus (em vez da especialização por disciplina ou, mesmo, do acompanhamento dos alunos ao longo de todo o curso de instrução primária) foi inspirada na experiência estrangeira. Ao que julgo saber, em Portugal, a especialização por graus nunca foi ensaiada fora do referido contexto casapiano.
} 
organizada (entre dois e oito graus)42; algo que, por vezes, está intimamente associado ao número de professores de cada escola. ${ }^{43}$

É certo que Eugénio de Almeida, à semelhança do que sucedeu com Victor Cousin e Henry Barnard, teve especial curiosidade pelo sistema educativo alemão (daí as viagens pedagógicas). Mas, ao contrário das duas últimas personalidades, não produziu qualquer relatório ou obra a esse respeito. Facto esse que, de modo óbvio, dificulta a análise do processo de transferência de conhecimento. Ainda assim, a partir do ano letivo de 1866/1867 é nítido que, para além da adoção de um modelo de organização pedagógica com seis graus, há outro ponto de contacto com a realidade dos Estados alemães. Refiro-me ao conceito de ensinar, sendo clara a recusa de qualquer ato mecânico e, mesmo, de apelo à memorização. Essa ideia está bem expressa na apreciação que Henry Barnard faz do plano de instrução primária de Baden: "The aim of the primary school is to cultivate the intellect of the child". ${ }^{44} \mathrm{E}$ acrescenta: "The pupil must have his attention sharpened, and his intellectual energies must be brought into activity. He must learn nothing mechanically. The memory must not be cultivated, except in connection with the understanding and the feelings". ${ }^{45}$ Ora, na Casa Pia de Lisboa o projeto de educação integral (no fundo, de articulação da educação física, intelectual e moral) concebido por Eugénio de Almeida e interpretado e posto em prática por Simões Raposo, alicerça-se, justamente, em semelhantes princípios. De resto, as "Instruções Escolares" que o provisor dos estudos elaborou em setembro de 1866 dão corpo à ideia veiculada por Henry Barnard. De facto, aquilo que se defende no referido documento é, nomeadamente, um "ensino real e não aparatoso" e a máxima ou lema "mais praticar que definir - mais compreender que decorar". ${ }^{46} \mathrm{~A}$ expressão maior deste entendimento encontra-se plasmada na base percetiva do ensino na sua concretização das "lições de coisas". Com efeito, o ensino percetivo obteve na Casa Pia de Lisboa um lugar autónomo no currículo desde 1866, emergindo a explicação de tal facto do próprio pensamento pedagógico de Simões Raposo:

\footnotetext{
A inteligência ou entendimento manifesta-se debaixo de uma série de operações que, no apurar da verdade, se dão na alma, tais são: perceção, atenção, juízo, raciocínio, memória, imaginação; se a inteligência se manifesta pelo conjunto destes poderes secundários, é claro que devem estes ser desenvolvidos e aperfeiçoados também no seu conjunto [...]

Desprezar umas [faculdades] para só cuidar de outras, sobrecarregar a memória das crianças com futilidades ou com abstrações sem aplicação imediata nos usos da vida e de reconhecida utilidade, é desmerecer, é menoscabar o título respeitoso e nobre de professor! $!^{47}$
}

\footnotetext{
${ }^{42}$ Daniel Töpper, "Der Weg zur Jahrgangsklasse - Zur Implementierung von Alter als Zuordnungs - und Gliederungseinheit im Schulwesen”, en Berlin-Brandenburger Beiträge zur Bildungsforschung, ed. Stiller et al. (Bern, Schweiz: Peter Lang, 2020), 139-163. Segundo o mesmo autor, foram comuns modelos de organização pedagógica de três a seis graus e, mesmo, de oito graus.

${ }^{43}$ É disso exemplo a organização pedagógica das escolas primárias de Baden, no início da década de 1860. Em causa, o nexo entre hierarquização dos graus (ou classes, se quisermos) e a idade dos alunos.

${ }^{44}$ Barnard, German schools and pedagogy, 210.

45 Ibidem.

${ }^{46}$ José António Simões Raposo, Relatorio das Aulas da Real Casa Pia de Lisboa (Lisboa, Typographia de M. da Costa, 1869), 28-29.

47 Ibidem, 12-13. É difícil perceber que interação pedagógica Eugénio de Almeida teve com Simões Raposo, se bem que este último, a partir de setembro de 1866, teve ampla margem de manobra na condução da reforma
} 
Termino sublinhando a seguinte ideia. Eugénio de Almeida tem o conhecimento e a plena consciência de que só a escola graduada permitia uma educação integral. Assim, o modelo de escola graduada, para além de dar resposta a um anseio de modernidade, nitidamente alinhado pela experiência alemã, vem a ser o que melhor corresponde ao projeto de integração social, se quisermos, de preparação para a vida (impossível esquecer aqui a prática do aprendizado), concebido pelo provedor José Maria Eugénio de Almeida, e muito justamente pelo facto das caraterísticas formais desse modelo (classificação dos alunos em classes o mais homogéneas possível, promoção rígida ao grau superior através de exame, graduação dos programas, rigoroso controlo do tempo ...) garantirem políticas de controlo e de eficiência escolar.

\section{Considerações finais}

Num momento inicial procurei traçar o perfil intelectual de José Maria Eugénio de Almeida, sublinhando o facto de ser um indivíduo culto e de se preparar bem para desempenhar os cargos para os quais era investido. Efetivamente, o processo de renovação pedagógica que vai ter lugar na Casa Pia de Lisboa a partir de meados da década de 1860 é alicerçado no conhecimento que o provedor da Casa Pia granjeou nas suas viagens (pedagógicas, em certo sentido) ao estrangeiro, designadamente, aos Estados alemães, assim como na leitura de diversos tratados e relatórios produzidos no campo educativo. Por outro lado, parece-me clara a influência que uma personalidade como Victor Cousin tem no pensamento pedagógico de Eugénio de Almeida, particularmente sentida na ênfase que põe na formação pedagógica do professorado. Outra questão importante é a que se prende com a circulação do conhecimento pedagógico. E aqui podemos falar em padrões de influência que se tornam referenciais para todos os países - considere-se a consolidação do modelo de escola graduada na segunda metade do século XIX. A convergência de influências estandardizadas é, sobretudo, visível nas mencionadas caraterísticas formais do modelo. Quer isso dizer que o conhecimento é muito resiliente. Tal assunção, no entanto, não pode fazer esquecer a produção de significados relacionados com o contexto de acolhimento. $\mathrm{Na}$ Casa Pia de Lisboa, os fenómenos de apropriação estão particularmente associados à integração social dos jovens e à preparação para a vida ativa.

\section{Bibliografia}

Caruso, Marcelo. "Locating educational authority, teaching monitors, educational meanings and the importing of pedagogical models. Spain and German States in the Nineteenth Century". En Educational Policy Borrowing: historical perspectives, editado por David Phillips and Kimberly Ochs, 59-87. Oxford: Symposium Books, 2004.

Costa, D. António da, Auroras da Instrucção pela Iniciativa Particular. Coimbra: Imprensa da Universidade, 1885.

Fonseca, Hélder e Reis, "José Maria Eugénio de Almeida, um capitalista da Regeneração", Análise Social, XXIII (99) (1987): 865-904.

educativa que então tem lugar. 
Justino, David. Fontismo. Liberalismo numa sociedade iliberal. Lisboa: D. Quixote, 2016.

Marvão, Fátima. Moralização, Trabalho e Educação. O Projecto Educativo da Casa Pia de Lisboa (1852-1922). Dissertação de mestrado, Universidade de Lisboa, 2004.

Morgan, Mary S., "Travelling Facts". En How Well do Facts Travel?, editado por Mary S. Morgan and Peter Howlett, 3-39. New York: Cambridge University Press, 2011.

Mota, Guilhermina. "O Visconde de Vila Maior: alguns apontamentos sobre a sua vida e ação". Biblos, X (2012): 246-292.

Nóvoa, António (dir.), Dicionário de Educadores Portugueses. Porto: ASA, 2003.

Phillips, David. "Toward a Theory of Policy Attraction in Education". En The Global Politics of Educational Borrowing and Lending, editado por Gita Steiner-Khamsi, 54-67. New York: Teachers College, Columbia University, 2004.

Sardica, José Miguel. José Maria Eugénio de Almeida: Negócios, Política e Sociedade no Século XIX. S.I.: Fundação Eugénio de Almeida, 2016.

Silva, Carlos Manique da. "A experiência do ensino mútuo na Casa Pia de Lisboa (18201859)", Cadernos de História da Educação, 8 (1) (2009): 85-101.

Silva, Carlos Manique da. Do modo de aprender e de ensinar: renovação pedagógica e cenários de experimentação da escola graduada (1834-1892). Tese de doutoramento, Universidade de Lisboa, 2008.

Töpper, Daniel, "Der Weg zur Jahrgangsklasse - Zur Implementierung von Alter als Zuordnungs - und Gliederungseinheit im Schulwesen". En Berlin-Brandenburger Beiträge zur Bildungsforschung, editado por J. Stiller, C. Laschke, T. Nesyba, and U. Salaschek, 139-163. Bern, Schweiz: Peter Lang, 2020.

Viñao, Antonio, "La Renovación de la Organización Escolar: la escuela graduada". En Psicología y pedagogía en la primera mitad del siglo XX, coordenado por Gabriela Ossenbach Sauter, 73-104. Madrid: UNED, 2003.

\section{Fontes documentais}

Manuscritas

Arquivo da Fundação Eugénio de Almeida, Catalogo Methodico da Livraria do llustríssimo e Excelentíssimo Senhor José Maria Eugenio de Almeida Organizado no anno de 1867 e Ampliado em 1873.

Arquivo da Fundação Eugénio de Almeida, "Contas das despesas pessoais, viagens a países estrangeiros...".

Arquivo da Fundação Eugénio de Almeida, "Fundo para as despesas das minhas viagens a países estrangeiros, em 1845". 
Arquivo Histórico da Casa Pia de Lisboa, Real Casa Pia de Lisboa, Livro de Registo dos Ofícios para Particulares, $\mathrm{n} . \stackrel{0}{1}$, 1859-1891.

Impressas

Almeida, José Maria Eugénio de. Relatorio da Administração da Real Casa Pia de Lisboa [de 20 de Out. de 1859 a 31 de Out. de 1860]. Lisboa: Imprensa Nacional, 1861.

Barnard, Henry. German schools and pedagogy. Organization and instruction of common schools in Germany. New York: F. C. Brownell, 1861.

Cousin, Victor. Report on the State of Public Instruction in Prussia. London: Effingham Wilson, Royal Exchange, 1836.

Ghira, Mariano. Relatorio sobre a visita de inspecção ás escolas do districto de Lisboa feita no anno lectivo de 1863-1864. Lisboa: Typographia Portugueza, 1865.

O Ex-Director da Casa Pia de Lisboa Francisco Antonio da Silva Neves e o Actual Director. Lisboa: Typographia da Bibliotheca Nacional, 1881.

Portarias da Administração da Real Casa Pia de Lisboa Publicadas pelo Provedor José Maria Eugénio de Almeida. Lisboa: Imprensa Nacional, 1862.

Raposo, José António Simões. Relatorio das Aulas da Real Casa Pia de Lisboa. Lisboa: Typographia de M. da Costa, 1869. 